\title{
An Odd Keloid Formation after Treatment of Congenital form of Boutonniere Finger
}

\author{
Hossein Akbari ${ }^{1} \quad$ Ali Foroutan ${ }^{1} \quad$ Peyman Akbari ${ }^{1} \quad$ Alireza Sherafat ${ }^{2} \quad$ Sayyed Abouzar Hosseini
}

\author{
${ }^{1}$ Hazrate Fatemeh Hospital, Iran University of Medical Sciences, \\ Tehran, Iran \\ ${ }^{2}$ School of Medicine, University of Central Lancashire, Preston, \\ United Kingdom
}

Indian J Plast Surg:2020;53:455-456

The focus of the present letter to editor is on keloid formation and its management following treatment of congenital form of Boutonniere finger. Keloids and hypertrophic scars represent fibroblast-mediated hyperactive response to dermal injuries that extend beyond the wound margins, causing functional and aesthetic impairments. ${ }^{1}$ Keloids most commonly develop on chest, ear lobe, shoulders, and upper arm. ${ }^{2,3}$ Lesions which extend beyond the wound borders are called keloids. ${ }^{4}$ They usually appear in areas such as ear, chest, and deltoid regions. ${ }^{2}$ They are usually the result of fibroblast abnormal proliferation and accumulation of excessive extracellular matrix during wound healing. ${ }^{3}$ Herein, we describe an atypical keloid on the finger of a 3-year old patient after treatment of congenital deformity.

Our patient was a 3-year old female with keloid formation following surgical treatment of congenital deformity. She initially presented with hyperextension in the distal interphalangeal (DIP) joint, a flexion contracture in the proximal interphalangeal (PIP) joint, and a decrease in range of motion in the metacarpophalangeal joint (MCP) in the 3rd digit of her right hand. This was a congenital form of Boutonniere deformity (-Fig. 1).

She underwent an operation in her second year of life. Open capsulotomy and reduction of joint displacement of both DIP and PIP were performed. Following releasing the contracture, central slip of extensor tendon was not found, which was reconstructed. The joint was kept extended with a k-wire insertion. After 6 weeks, the pin was removed, and hand physiotherapy was started.

We noted a keloid forming on the dorsal surface of the middle and distal phalanges of the right middle finger during follow-up assessment in clinic after 3 months ( - Fig. 2). Since the lesion started to grow, three courses of intralesional

\author{
Address for correspondence Ali Foroutan, MD, Hazrate Fatemeh \\ Hospital, Iran University of Medical Sciences, Tehran, Iran \\ (e-mail: Aliforoutanplastic@gmail.com).
}

triamcinolone were injected every 4 weeks. However, the lesion continued to grow vertically up to $4.5 \mathrm{~cm}$ in height and had an odd finger-like appearance ( - Fig. $\mathbf{3}$ ).

The patient had no history of any keloid formation before. The history and physical examination were otherwise unremarkable.

Due to the functional impairments and enlarged size, the keloid was resected and sent to the pathology department for histopathological examination. The specimen was reported to be fibroconnective tissue with acidophilic bands of hyalinized collagen. In addition, fibroblasts associated with thin-wall blood vessels in the background were reported. The thickened hyalinized collagen bundles that were reported histologically are indicative hallmarks of keloid formation. The child was followed up for 8 months after excision of keloid. The excision was successful in terms of function and structure ( $\boldsymbol{- F i g . 4}$ ). However, some extension contracture remained on distal interphalangeal joint, due to the effect of keloid. Hence, physical therapy is continued for her.

Keloids are rare on digits and only 23 cases have been reported in 10 studies, with most of them appearing following syndactyly treatment. ${ }^{5}$ There have been no reports on keloid formation after congenital form of Boutonniere deformity. There is no consistent standard treatment available for keloids formed in the toes and fingers. In 2014, Yamawaki et al stated that a keloid formation after syndactyly release was treated with surgical excision and intralesional steroid injection..$^{5}$ Some studies used skin grafts or regional flaps to cover the defect after keloid resection. Direct closure was performed in 6 cases. ${ }^{5}$ We treated this keloid with multiple intralesional triamcinolone injection and surgical resection successfully. published online

December 28, 2020
DOI https://doi.org/

$10.1055 / \mathrm{s}-0040-1721861$

ISSN 0970-0358.
C2020. Association of Plastic Surgeons of India.

This is an open access article published by Thieme under the terms of the Creative Commons Attribution-NonDerivative-NonCommercial-License, permitting copying and reproduction so long as the original work is given appropriate credit. Contents may not be used for commercial purposes, or adapted, remixed, transformed or built upon. (https://creativecommons.org/licenses/by-nc-nd/4.0/).

Thieme Medical and Scientific Publishers Pvt. Ltd. A-12, 2nd Floor, Sector 2, Noida-201301 UP, India 


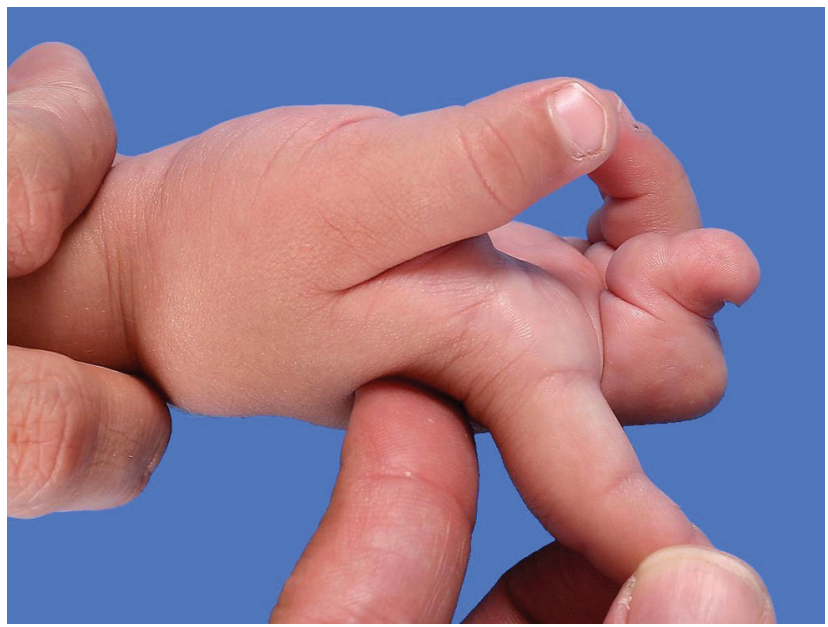

Fig. 1 Congenital Boutonniere deformity of third digit prior to operation

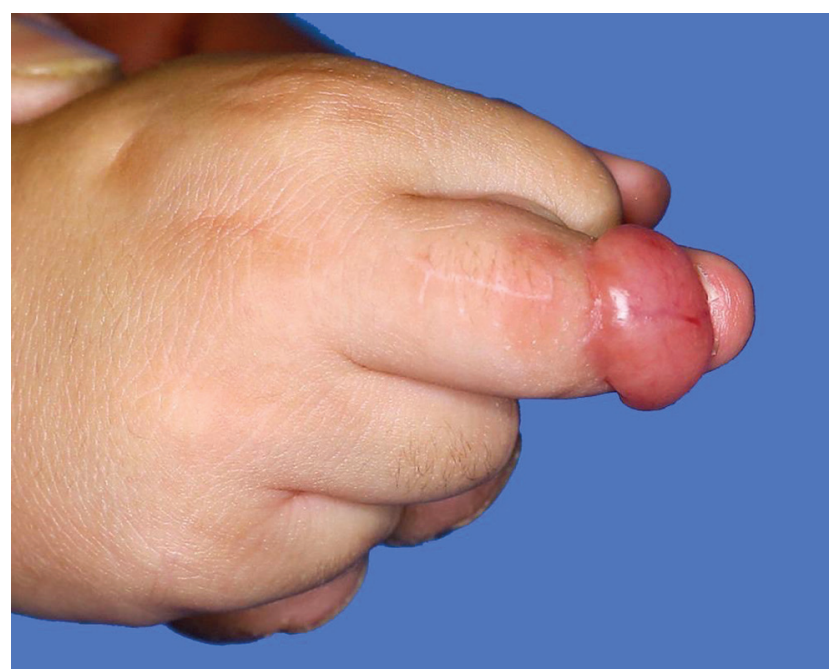

Fig. 2 The keloid which appeared following treatment of congenital Boutonniere deformity.

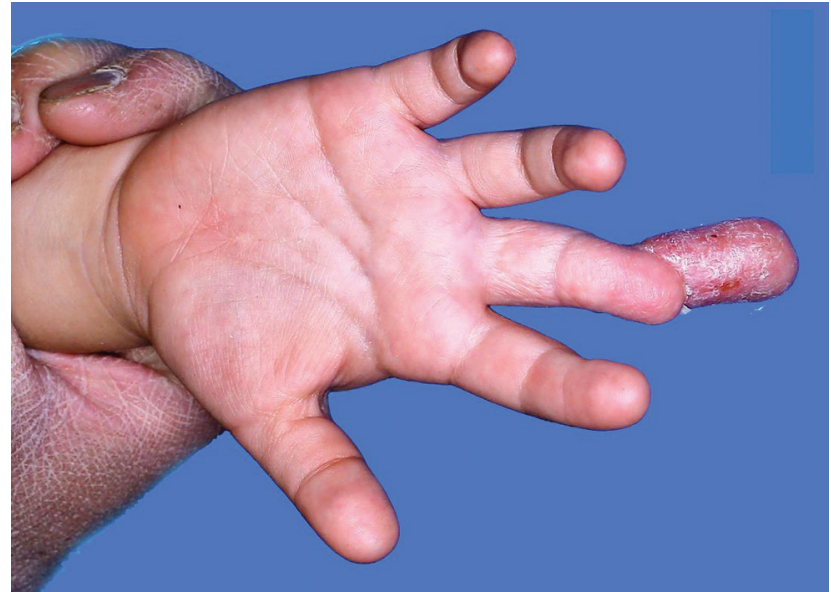

Fig. 3 The keloid increased in size within the next 5 months, following successful treatment of congenital Boutonniere deformity.

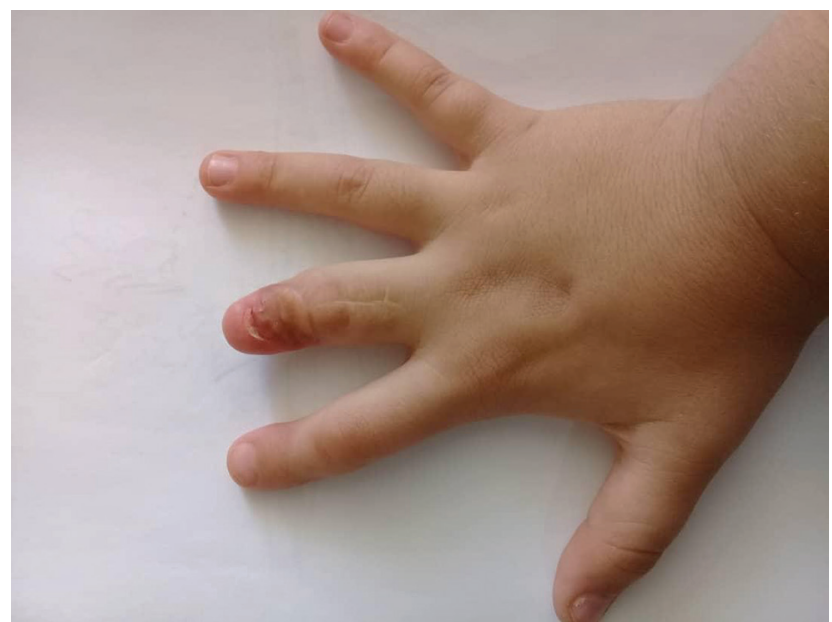

Fig. 4 The third digit appearance after excision of the keloid during the follow-up visit in 8 months.

\section{Conflicts of Interest}

None declared.

\section{References}

1 Mahdavian Delavary B, van der Veer WM, Ferreira JA, Niessen FB. Formation of hypertrophic scars: evolution and susceptibility. J Plast Surg Hand Surg 2012;46(2):95-101

2 Nemeth AJ. Keloids and hypertrophic scars. J Dermatol Surg Oncol 1993;19(8):738-746

3 Gauglitz GG. Management of keloids and hypertrophic scars: current and emerging options. Clin Cosmet Investig Dermatol 2013;6:103-114

4 Wong TS, Li JZ, Chen S, Chan JY, Gao W. The efficacy of triamcinolone acetonide in keloid treatment: a systematic review and meta-analysis. Front Med (Lausanne) 2016;3:71

5 Yamawaki S, Naitoh M, Ishiko T, Aya R, Katayama Y, Suzuki S. A toe keloid after syndactyly release treated with surgical excision and intralesional steroid injection. Plast Reconstr Surg Glob Open 2014;2(7):e186 